Check for updates

London

Cite this as: $B M J$ 2021;372:n829 http://dx.doi.org/10.1136/bmj.n829 Published: 25 March 2021

\section{Covid-19: Middle aged women face greater risk of debilitating long term symptoms}

\author{
Ingrid Torjesen
}

Middle aged women have a higher risk of experiencing a range of debilitating ongoing symptoms, such as fatigue, breathlessness, muscle pain, anxiety, depression, and "brain fog" after hospital treatment for covid-19, suggest the findings of two unpublished studies available as preprints.

Seven in 10 patients admitted to hospital with covid-19 reported "long covid" symptoms an average of five months after discharge in the larger PHOSP-COVID study, and symptoms were more prevalent in women aged 40-60. ${ }^{1}$ White ethnicity, two or more comorbidities at admission, and receiving invasive ventilation while in hospital increased the risk, but severity of acute covid-19 disease did not seem to affect the likelihood of experiencing long covid symptoms.

Only $29 \%$ of the 1077 patients studied felt fully recovered when followed up, on average five months after discharge. Over a quarter had clinically significant symptoms of anxiety and depression, $12 \%$ had symptoms of post-traumatic stress disorder, $17 \%$ had at least mild cognitive impairment, $46 \%$ had lower physical performance than age and sex matched controls, and 20\% had a new disability.

Before hospital admission $68 \%$ of patients had worked full time, but $18 \%$ of these had not returned to work and $19 \%$ had had to change their way of working because of longlasting effects.

The researchers grouped patients into four clusters according to the severity of their physical and mental symptoms post-covid: very severe ( $17 \%$ of patients), severe $(21 \%)$, moderate with cognitive impairment (17\%), and mild (46\%).

Rachael Evans, National Institute for Health Research clinical scientist at the University of Leicester and a study author, said, "The symptoms are very real, but they don't have a straightforward relationship with heart and lung damage, or certainly heart and lung damage can't explain all the symptoms."

\section{Immune response}

A smaller second study, from the International Severe Acute Respiratory and emerging Infections Consortium (ISARIC), found that women under 50 were five times less likely to report feeling recovered, twice as likely to report worse fatigue, seven times more likely to become more breathless, and more likely to have greater disability than men of the same age who had been admitted to hospital with covid-19. ${ }^{2}$ Disability usually affected memory, mobility, communication, vision, or hearing. More than half of the 327 patients assessed in this study did not feel fully recovered when followed up on average seven months later, and persistent symptoms were reported by $93.3 \%$, with fatigue and breathlessness the most common.

Chris Brightling, professor of respiratory medicine at the University of Leicester and a PHOSP-COVID study researcher, speculated that sex based differences in the immune response may be responsible for the higher prevalence of long covid symptoms in women, noting that autoimmune diseases were more prevalent in women than in men at age 40-60.

"Maybe there's a difference in the immune response acutely, such that men are more likely to have a more severe condition at the time of the infection," he told a press conference at the Science Media Centre on 24 March. "It may be that the immune response is different in women, so you then have a continued inflammatory reaction that then leads to a higher likelihood of having long covid."

Higher levels of $\mathrm{C}$ reactive protein, a marker of systemic inflammation, were seen in patients in the most severe long covid symptoms. Brightling said that a number of immune and chronic inflammatory conditions can also cause elevated $\mathrm{C}$ reactive protein.

About 450 ooo people have been admitted to hospital with covid-19 in the UK, so a "very large" proportion of these would potentially be affected by long covid, he said, adding, "Clearly there's an even larger number of people that have had covid in the community, and a portion of those will also have long covid.”

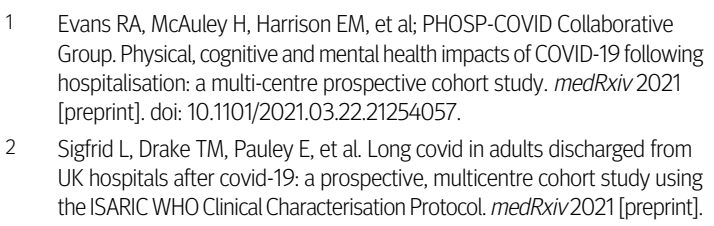

Evans RA, McAuley H, Harrison EM, et al; PHOSP-COVID Collaborative Group. Physical, cognitive and mental health impacts of COVID-19 following hospitalisation: a multi-centre prospective cohort study. medRxiv 2021 [preprint]. doi: 10.1101/2021.03.22.21254057.

2 Sigfrid L, Drake TM, Pauley E, et al. Long covid in adults discharged from UK hospitals after covid-19: a prospective, multicentre cohort study using the ISARIC WHO Clinical Characterisation Protocol. medRxiv2021 [preprint]. doi: 10.1101/2021.03.18.21253888.

This article is made freely available for use in accordance with BMJ's website terms and conditions for the duration of the covid-19 pandemic or until otherwise determined by BMJ. You may use, download and print the article for any lawful, non-commercial purpose (including text and data mining) provided that all copyright notices and trade marks are retained. 